\title{
Rhinocerebral mucormycosis secondary to severe acute pancreatitis and diabetic ketoacidosis: a case report
}

\author{
Jinjing Wang, Yao Li, Shuai Luo and Hong Zheng*
}

\begin{abstract}
Introduction: Rhinocerebral mucormycosis is a rare and severe form of opportunistic fungal infection that can develop rapidly and cause significant mortality, particularly among diabetic patients suffering from ketoacidosis. Diagnosing rhinocerebral mucormycosis during the early stages of infection is challenging.

Case presentation: We describe a case of rhinocerebral mucormycosis secondary to severe acute pancreatitis in a patient suffering from diabetic ketoacidosis. In this case, the condition was not diagnosed during the optimal treatment window. we therefore provide a thorough overview of related clinical findings and histopathological characteristics, and we discuss potential differential diagnoses.

Conclusions: In summary, we described a case of rhinocerebral mucormycosis secondary to severe acute pancreatitis in a patient suffering from diabetic ketoacidosis, with the optimal treatment window for this condition having been missed. This report suggests that a definitive mucormycosis diagnosis can be made based upon tissue biopsy that reveals the presence of characteristic hyphae. Early diagnosis and treatment are essential in order to improve patient prognosis.
\end{abstract}

Keywords: Rhinocerebral mucormycosis, Severe acute pancreatitis, Diagnosis, Pathology, Case report

\section{Introduction}

Rhinocerebral mucormycosis is a rare and severe form of opportunistic fungal infection that can develop rapidly and cause significant mortality, particularly among diabetic patients suffering from ketoacidosis $[1,2]$. As the initial clinical symptoms of mucormycosis can be nonspecific and inconsistent, diagnosis is often delayed and rates of misdiagnosis are high such that the condition is not often treated effectively during the optimal treatment window [3]. The development of novel approaches to diagnosing and treating this condition during its early stages is thus essential in order to minimize patient morbidity and mortality [3].

\footnotetext{
*Correspondence: 313571974@qq.com

Department of Pathology, The Affiliated Hospital of Zunyi Medical University, Zunyi City, Guizhou Province, P.R. China
}

Herein, we describe a case of rhinocerebral mucormycosis secondary to severe acute pancreatitis in a patient suffering from diabetic ketoacidosis. In this case, the condition was not diagnosed during the optimal treatment window. To improve current understanding of this condition and to better improve future diagnostic accuracy, we therefore provide a thorough overview of related clinical findings and histopathological characteristics, and we discuss potential differential diagnoses.

\section{Case presentation}

A 38 years old male patient with uncontrolled diabetes was admitted to our hospital complaining of severe abdominal pain after meals with nausea and vomiting. Laboratory analyses revealed high $(+++)$ urinary ketone body levels, elevated $(+)$ levels of urine glucose, and $24 \mathrm{~h}$ blood glucose fluctuations from $16.0-21.6 \mathrm{mmol} / \mathrm{L}$.

(c) The Author(s). 2021 Open Access This article is licensed under a Creative Commons Attribution 4.0 International License, which permits use, sharing, adaptation, distribution and reproduction in any medium or format, as long as you give appropriate credit to the original author(s) and the source, provide a link to the Creative Commons licence, and indicate if changes were made. The images or other third party material in this article are included in the article's Creative Commons. licence, unless indicated otherwise in a credit line to the material. If material is not included in the article's Creative Commons licence and your intended use is not permitted by statutory regulation or exceeds the permitted use, you will need to obtain permission directly from the copyright holder. To view a copy of this licence, visit http://creativecommons.org/licenses/by/4.0/ The Creative Commons Public Domain Dedication waiver (http://creativecommons.org/publicdomain/zero/1.0/) applies to the data made available in this article, unless otherwise stated in a credit line to the data. 

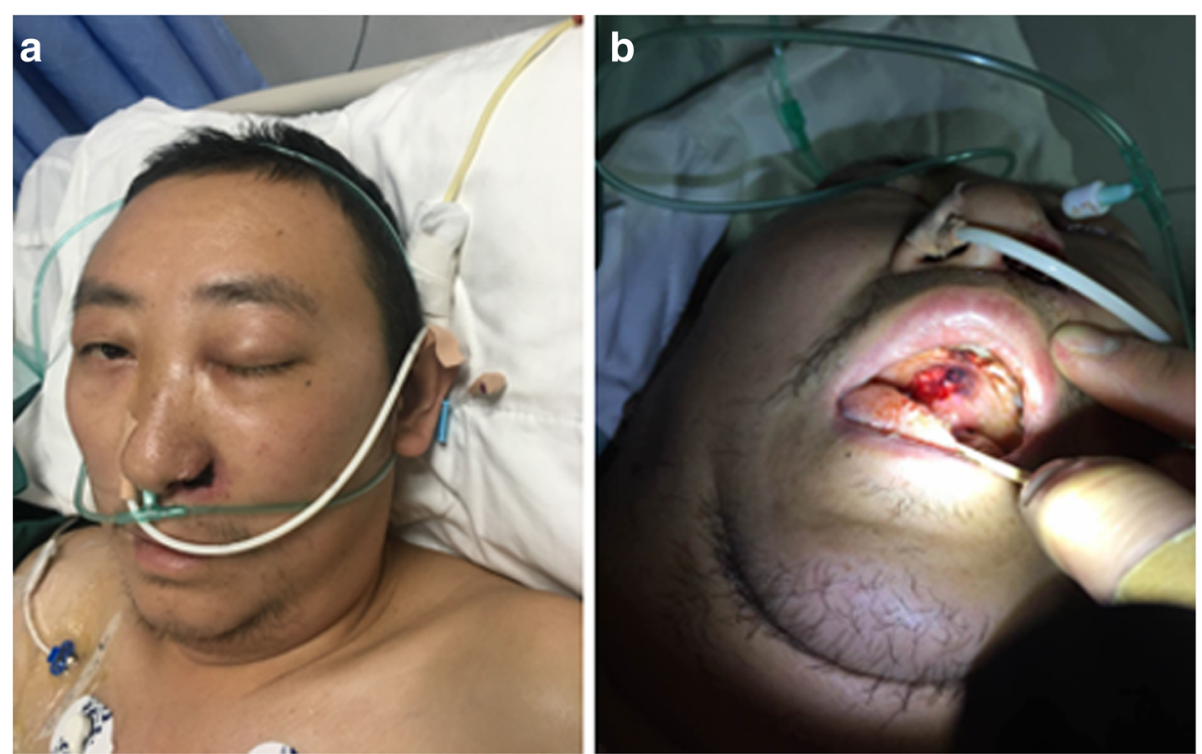

Fig. 1 a Necrosis of the left nasal wing, welling of the left eye, and right side paralysis were detected. $\mathbf{b}$ Hard palate perforation

Abdominal enhanced computed tomography (CT) imaging revealed evidence of acute pancreatitis and peritoneal fluid accumulation. The patient was therefore diagnosed with acute pancreatitis, hyperlipidemia, and diabetic ketoacidosis. However, 5 days later, dark necrotic tissue was observed in the left nasal cavity of this patient. At this same time point, the tissue on the left side of his face was visibly swollen, with left orbital proptosis, eyelid drooping, complete ophthalmoplegia, and dilation of his right pupil with a marked reduction in visual acuity (Fig. 1). CT analyses revealed an increase in soft tissue density in the patient's bilateral maxillary sinus, ethmoid sinus, sphenoid sinus, and right frontal sinusitis. Dilatation of his left medial and inferior recti was observed, and the perforation of the patient's nasal septum was observed, affecting his left nasal cavity. Hard palate perforation was also observed (Fig. 2). Nasoendoscopy revealed large quantities of dark necrotic tissue within the bilateral nasal cavity. The majority of the soft tissue within the nasal cavity was damaged, with complete exposure of the bones of the nasal floor and the lower nasal passage, and with complete exposure of
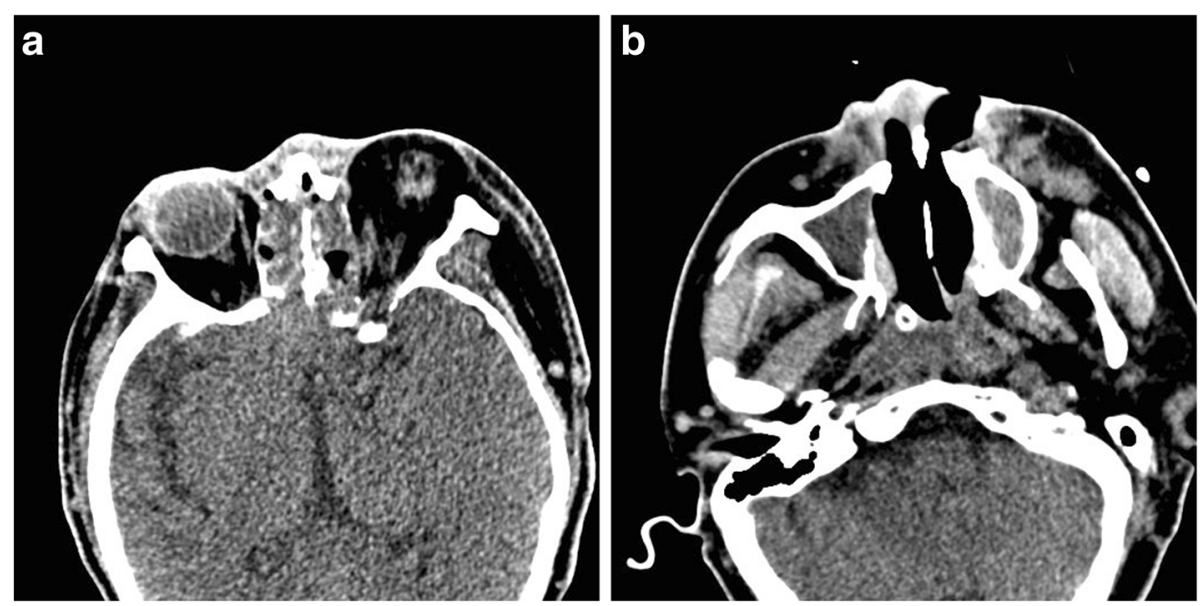

Fig. 2 a Computed tomography (CT) scanning of the brain and orbits revealed extensive involvement of the bilateral intranasal sinuses, orbits, extraocular muscles, and soft tissues. Increased soft tissue density was evident in the bilateral maxillary sinus, ethmoid sinus, sphenoid sinus, and around the orbits. Dilatation of the extraocular muscles was also observed, as was erosion of the left lateral wall of the sphenoid and cribriform plate. $\mathbf{b}$ Perforation of the patient's nasal septum affected the left nasal cavity, with evidence of hard palate and left nasal wing involvement and perforation 


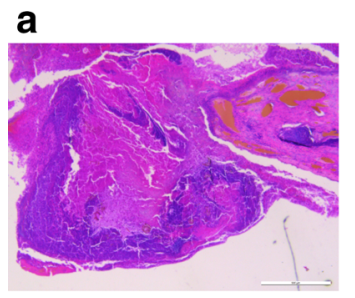

b

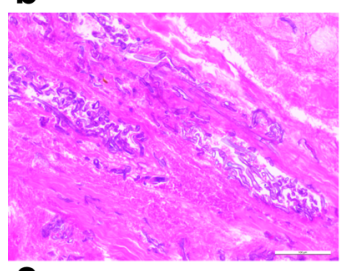

C
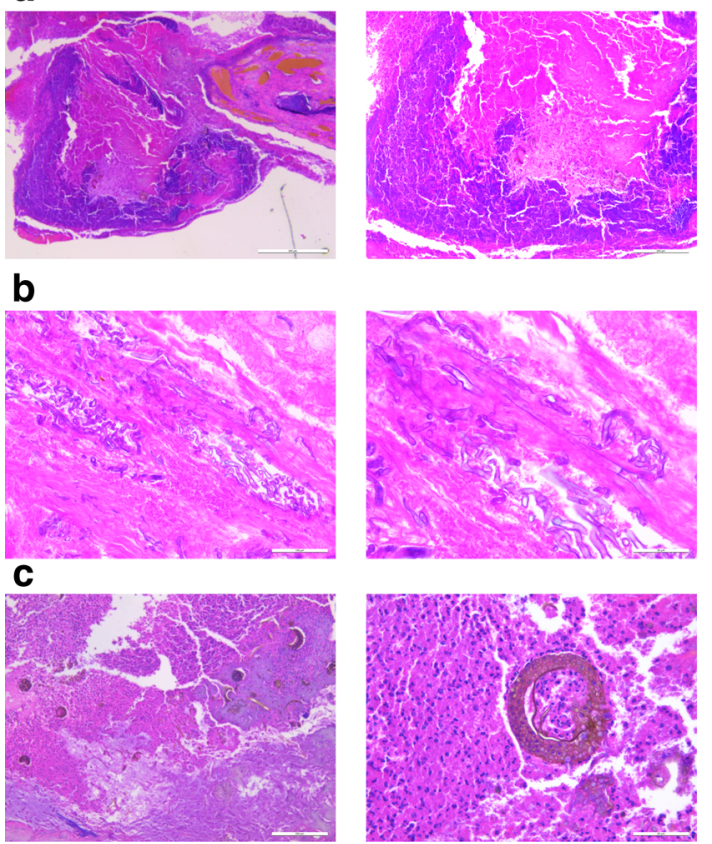

d

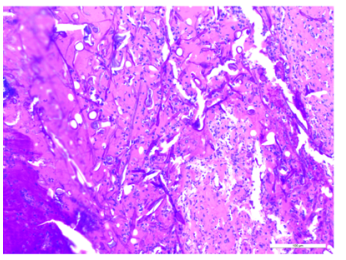

e

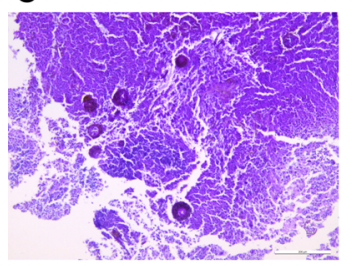

f

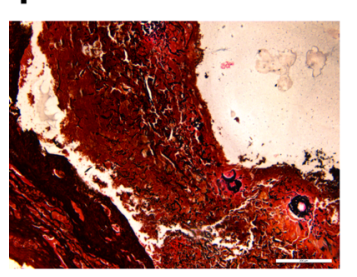

g

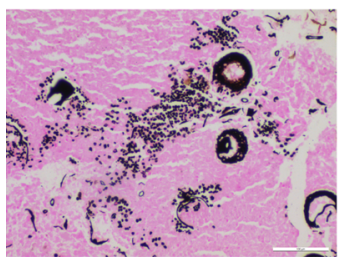

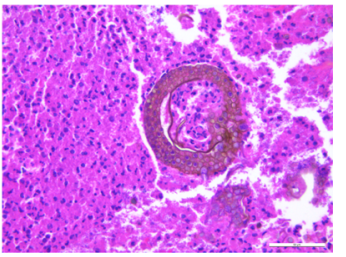
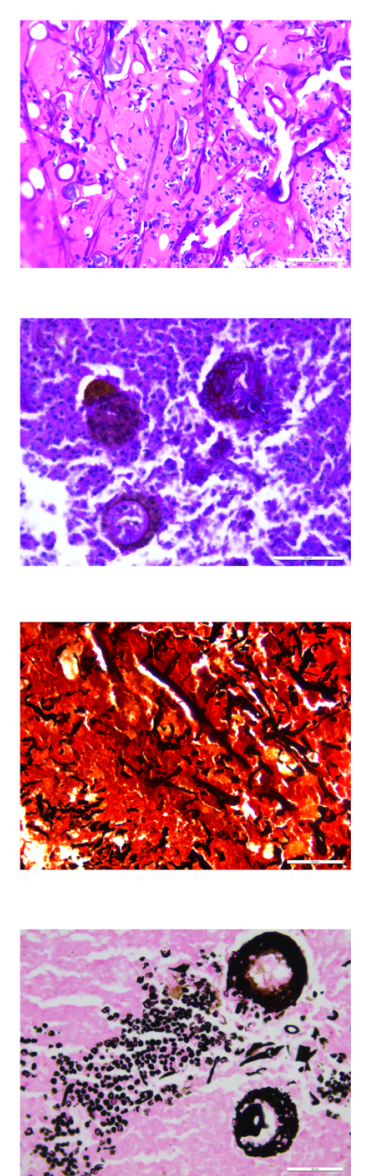

Fig. 3 a Coagulated necrotic soft tissue was assessed via microscopy, revealing the presence of lymphocytes, plasma cells, and multinucleated giant cells in the necrotic tissue (A1 H\&E stain $x$ 50; A2 H\&E stain $\times 100$ ). b Many hyphae were detected in necrotic soft tissue samples, surrounding and invading the walls of blood vessels, thereby resulting in vasculitis and thrombus formation (B1 H\&E stain $\times 200$; B2 H\&E stain $\times 400$ ). c Mucorales were characterized by small round brown spores and basophilic chrysanthemum-like sporangium exhibiting sporangiospores and sporangiophores (C1 H\&E stain $\times 100$; C2 H\&E stain $\times 400$ ). $\mathbf{d}$-g Periodic-acid-Schiff (PAS) staining revealed fungal hyphae that were pink (D1 PAS stain $\times 200$; D2 PAS stain $\times 400$ ), spores that were yellow-brown (E1 PAS stain $x$ 200; E2 PAS stain $\times 400$ ). Grocott staining highlighted hyphae (F1 Grocott stain $\times 100$; F2 Grocott stain $\times 400$ ), sporangia, and spores that were noticeably dark brown (G1 Grocott stain $\times 100$; G2 Grocott stain $\times 400$ ). H\&E: Hematoxylin and eosin

the lower nasal passage. The top of the nasal cavity was also affected. A sample of the observed dark necrotic soft tissue was excised for pathological examination.

Histopathological examination revealed that the coagulated necrotic tissue contained lymphocytes, plasma cells, and multinucleated giant cells (Fig. 3A1, 2). Many hyphae were visible surrounding and invading blood vessel walls, resulting in vasculitis and thrombus formation (Fig. 3B1, 2). Broad tubular hyphae that were $20-30 \mu \mathrm{m}$ wide were observed, with two asymmetric sidewalls that were partially swollen and distorted without separation, aside from a few disorderly branches occurring at right angles (Fig. 3B2). Sporangia were characterized by small round brown spores and basophilia chrysanthemumcluster-like sporangium, with visible endospores in the sac. Individual spores were roughly $10 \mu \mathrm{m}$ in diameter, and were densely arranged in sheets (Fig. 3C1, 2). Periodic-acid-Schiff (PAS) staining revealed pink fungal hyphae (Fig. 3D1-2), and yellow-brown spores (Fig. 3E1, 2). Grocott staining highlighted hyphae (Fig. 3F1, 2), sporangia, and spores, which were a noticeable dark brown color (Fig. 3G1, 2). Such fungal morphology was suggestive of a Mucor fungus, and the patient was pathologically diagnosed with acute invasive mucormycosis. He was treated via surgical debridement combined with intravenous amphotericin B administration. However, due to his advanced disease progression, the patient died 4 weeks following admission.

\section{Discussion and conclusions}

Rhinocerebral mucormycosis is a rare, aggressive, and life-threatening fungal infection [4], occurring most often in diabetes patients suffering from ketoacidosis [5]. At present, owing to the nonspecific early-stage symptoms of this disease, it is difficult to diagnose until it is relatively advanced.

Ocular manifestations are often the first presenting symptoms in patients suffering from rhinocerebral 
mucormycosis. These symptoms can include prominent eyeballs, swelling and redness around the eyes, impaired eye movement, decreased vision, and potentially blindness. Nasal black eschar formation is one of the most important clinical findings associated with rhinocerebral mucormycosis [4]. CT or magnetic resonance imaging (MRI) examinations of the skull generally reveal the thickening of the sinus mucosa, sinusitis, bone destruction, and cavernous sinus thrombosis. These findings may be accompanied by facial swelling and numbness, local facial skin ulceration, local black necrotic eschar formation, and black eschar or ulcers on the epiphysis.

There are several approaches that can be used to diagnose rhinocerebral mucormycosis. Fungal culture is highly specific, but the sensitivity of this approach is just $25 \%$, limiting its clinical applicability [6]. Pathological assessment of biopsy samples can achieve a more definitive diagnosis, as affected patients generally exhibit large areas of coagulative necrotic tissue, fungal granuloma, fungal vasculitis, thrombosis, and bone destruction [5, 6]. Typical granulomatous tissues from affected patients generally contain hyphae and neutrophils surrounded by epithelioid cells, multinucleated giant cells, varying numbers of plasma cells, lymphocytes, and eosinophils. Perivascular and blood vessel invasion by fungal hyphae results in arterial thrombosis and subsequent necrosis. Hyphae are generally broad and irregularly shaped, with branches primarily forming at right angles [6]. Hematoxylin and eosin staining of these hyphae largely fails to differentiate them from background tissues, and high magnification is often necessary to clearly resolve these fungal structures. PAS and Gomori methenamine silver (GMS) staining result in the purple-red and brown-black coloration to these hyphae, respectively, making them easier to observe $[4,6]$. Molecular biology approaches can also be used to diagnose this condition, although it remains challenging to leverage a broadspectrum for the diagnosis of mucormycosis in clinical settings [6].

From a differential diagnosis perspective, rhinocerebral mucormycosis may be confused with other forms of fungal sinusitis. Identification is mainly based on the morphological characteristics of fungal hyphae. Mucor mycelia are relatively thick $(6-25 \mu \mathrm{m}$ in diameter) and disordered, with thick walls, asymmetry, little separation, partial swelling and twisting, and relatively few branches that are primarily at right angles $[5,6]$. In contrast, Candida mycelia are thin (2 - $4 \mu \mathrm{m}$ in diameter) and can be bead-like [6], while Aspergillus mycelia are of medium thickness (5$10 \mu \mathrm{m}$ in diameter), uniform in thickness, often exhibit directional growth, are frequently separated, and generally exhibit many branches that are most often formed at acute angles [3].
Treatment options for rhinocerebral mucormycosis include the active treatment of primary disease, correction of underlying acidosis, and the early administration of agents including amphotericin B liposomes, together with the thorough debridement of local necrotic tissue [6]. Surgical and antifungal treatments generally form the cornerstones of treatment [4], and delays in initiating amphotericin B treatment for more than 6 days is associated with a doubling of mortality at 12 weeks.

In summary, we described a case of rhinocerebral mucormycosis secondary to severe acute pancreatitis in a patient suffering from diabetic ketoacidosis, with the optimal treatment window for this condition having been missed. This report suggests that a definitive mucormycosis diagnosis can be made based upon tissue biopsy that reveals the presence of characteristic hyphae. Early diagnosis and treatment are essential in order to improve patient prognosis.

\section{Abbreviations}

CT: Computed tomography; MRI: Magnetic resonance imaging; PAS: Periodicacid-Schiff; GMS: Gomori methenamine silver

\section{Acknowledgements}

This Project Supported by Guizhou Science Foundation (No. QKHLH20157455 and No. 1Y429,) and a science grant from Zunyi Medical University (No. 2018KY36). The authors would like to thank Editage (editage.com) for English language editing.

\section{Authors' contributions}

Resources: Shuai luo, Yao Li, Writing - original draft: Jinjing Wang. Writing review \& editing: Jinjing Wang, Hong Zheng. All the authors have read \& approved the final manuscript.

Availability of data and materials

All the data regarding the findings are available within the manuscript.

\section{Declarations}

Ethics approval and consent to participate

This case report was approved by the Ethics Committee of the Affiliated Hospital of Zunyi Medical University. Written informed consent was obtained from the patient for publication of this clinical case report.

\section{Consent for publication}

Written informed consent was obtained from the family of the patient for publication of this case report and any accompanying images.

\section{Competing interests}

The authors declare that they have no competing interests.

Received: 28 December 2020 Accepted: 31 March 2021 Published online: 21 April 2021

\section{References}

1. Zaher FZ, et al. Diabetic ketoacidosis revealing a severe hypertriglyceridemia and acute pancreatitis in type 1 diabetes mellitus. Case Rep Endocrinol. 2019:2019:8974619.

2. Suh IW, et al. Hepatic and small bowel mucormycosis after chemotherapy in a patient with acute lymphocytic leukemia. J Korean Med Sci. 2000;15(3): $351-4$.

3. Sahota $\mathrm{R}$, et al. Rhinocerebral Mucormycosis: report of a rare case. Ethiop J Health Sci. 2017;27(1):85-90. 
4. Galletti B, Gazia F, Galletti C, Perani F, Ciodaro F, Freni F, et al. Rhinocerebral mucormycosis with dissemination to pontine area in a diabetic patient: Treatment and management. Clin Case Rep. 2019;7(7):1382-7. https://doi. org/10.1002/ccr3.2255 PMID: 31360493; PMCID: PMC6637368.

5. Corzo-Leon DE, et al. Diabetes mellitus as the major risk factor for mucormycosis in Mexico: epidemiology, diagnosis, and outcomes of reported cases. Med Mycol. 2018;56(1):29-43.

6. Bavikar P, Mehta V. Rhino-orbital-cerebral Mucormycosis: a fatal complication of uncontrolled diabetes mellitus. Cureus. 2017;9(11):e1841.

\section{Publisher's Note}

Springer Nature remains neutral with regard to jurisdictional claims in published maps and institutional affiliations.

Ready to submit your research? Choose BMC and benefit from:

- fast, convenient online submission

- thorough peer review by experienced researchers in your field

- rapid publication on acceptance

- support for research data, including large and complex data types

- gold Open Access which fosters wider collaboration and increased citations

- maximum visibility for your research: over $100 \mathrm{M}$ website views per year

At BMC, research is always in progress.

Learn more biomedcentral.com/submissions 